\title{
NURSING HOME VULNERABILITIES AMID COVID-19 PANDEMIC: A STUDY OF MIDWESTERN STATES
}

\author{
P. NAMBISAN 1 , M. ABAHUSSAIN ${ }^{1,6}$, E.H. DUTHIE ${ }^{2}$, C. GALAMBOS 3 , B. ZHANG ${ }^{4}$, E. BUKOWY5 \\ 1. Department of Health Informatics \& Administration, College of Health Sciences, University of Wisconsin - Milwaukee, Milwaukee, USA; 2. Medical College of Wisconsin \\ Division of Geriatric and Palliative Medicine, Milwaukee, USA; 3. Helen Bader School of Social Welfare, University of Wisconsin Milwaukee, Medical College of Wisconsin, \\ Milwaukee, Wisconsin, USA; 4. Educational Measurement, Department of Educational Psychology, University of Wisconsin-Milwaukee, Milwaukee, Wisconsin, USA; 5. Division of \\ Geriatric and Palliative Medicine, MCW \& Froedtert Hospital, Medical Director for the Lutheran Home and Clement Manor Nursing Home, Milwaukee, Wisconsin, USA; \\ 6. Department of Ambulance Services, Prince Sultan Bin Abdulaziz College for Emergency Medical Services, King Saud University, Riyadh, Saudi Arabia. Corresponding author: Priya \\ Nambisan, Department of Health Informatics \& Administration, College of Health Sciences, University of Wisconsin - Milwaukee, Northwest Quadrant Building B, Rm \#6410, 2025 \\ East Newport Avenue, Milwaukee, WI 53201-0413, Phone: (414) 251-0421, Office Ph: (414) 251-5217; Email: nambisap@uwm.edu
}

\begin{abstract}
Background: The COVID-19 pandemic disproportionately affected the older adult population, especially those in nursing homes (NHs). However, there is also evidence that some NHs fared better than others. Objectives: This study examines a set of nursing home related factors to understand whether these factors are associated with the number of COVID-19 cases. Design: We combined three datasets from the Centers for Medicare \& Medicaid Services (CMS) - the Star Rating Dataset, the Provider Information Dataset, and the COVID-19 Nursing Home Dataset. Setting and Participants: 4390 NHs that responded to the CMS survey. Methods: Data used is from the period of Jan 1-Dec 27, 2020 for all 12 Midwestern states. The measures used were self-reported information on ratings, staff shortages, PPE shortage, number of beds, Registered Nurse (RN), Licensed Practical Nurses (LPN), Certified Nursing Assistants (CNA) hours per resident, star rating and ownership. Results: Of the $4390 \mathrm{NHs}$ in 12 Midwestern states, high performing NHs were less likely to have more than 30 COVID-19 cases versus low-performing facilities for two of the CMS domains (health inspections, $520 \mathrm{NHs}$ [27.6\%] vs $1363 \mathrm{NHs}$ [72.4\%]; and staffing $773 \mathrm{NHs}$ [41.1\%] vs 1110 NHs [58.9\%]). There was also a statistically significant association COVID-19 cases and star rating, NH ownership, NH size, RN, LPN, and CNA staffing in NHs (all p $\leq 0.01$ ). NH ownership status persisted as a predictor of COVID 19 cases when controlled for NH size. Conclusions: Our study highlights two interesting findings. A) a statistically significant association between NH ownership structure and COVID-19 cases among residents - for-profit NHs had higher number of COVID-19 cases B) a statistically significant negative association between RN and CNA staffing and COVID-19 cases (i.e., more staffing hours of RNs and CNA correlated with a smaller number of COVID-19 cases) and a statistically significant positive association between LPN staffing and COVID-19 cases. We discuss ensuing policy implications for NHs.
\end{abstract}

Key words: COVID-19, Nursing homes, staffing hours, for-profit nursing homes.

\section{Introduction}

The COVID-19 pandemic disproportionally affected the older adult population, especially those in nursing homes (NHs). According to a recent AARP report, an estimated 174,000 residents and staff of nursing homes and other longterm care facilities across the country died due to COVID-19 (1). Further complicating the situation, there are reports of under-reporting of nursing home deaths due to COVID-19 from many states (2). While many NHs were reporting COVID-19 cases to state and local public health departments, it was not until April 2020 that they started reporting to the CDC in a standardized format, which may have led to under or inaccurate reporting (3).

To understand how older adults can be protected in nursing homes, it is important to consider the characteristics that make some nursing homes more susceptible to the spread of COVID19. In many ways, the COVID-19 pandemic has exposed the existing weaknesses of the nursing home system which provides care to some of the frailest and most vulnerable individuals in our society. Some researchers have called this pandemic a 'case study of infection control' (4) and studies delving into the factors that contributed to devastating outbreaks can provide critical insights into how this can be prevented in the future.

Nursing homes are prone to infectious outbreaks (e.g., seasonal influenza, norovirus) and there are several factors that make nursing homes highly vulnerable. These factors could range from high number of residents causing crowding, shared bathroom facilities, gathering/common areas to staffing shortages, frequent staff turnover, high resident-to-staff ratios, shortage of PPE, inadequate quality control and poor management $(4,5)$. In addition, $\mathrm{NH}$ residents are typically older adults with multiple chronic conditions such as diabetes, heart disease, pulmonary disease and other functional and cognitive disabilities including frailty $(6,7)$. Individuals with underlying chronic conditions were particularly vulnerable to contracting COVID-19 (8). Additionally, staff and caregivers in NHs are underpaid, do not get sick leave and move from resident to resident without adequate sanitation control or PPE 


\section{NURSING HOME VULNERABILITIES AMID COVID-19 PANDEMIC}

$(4,9)$. Given that staff turnover rates are very high in nursing homes, training and maintaining sanitary protocols can also be challenging in this environment (4).

Using datasets available from CMS, which consists of selfreported data from $\mathrm{NHs}$ around the country on various factors, many studies (10-14) have reported findings on the factors associated with nursing homes and COVID-19 cases for various time periods in 2020. There have also been several single-state studies e.g. California (15), Connecticut (16) and West Virginia (17), that considered various factors such as star ratings, staffing, CMS quality indicators and PPE shortage. While data from CMS have been analyzed for NHs in Northeastern states $(18)$ and for 30 States $(11,12)$, no studies have yet focused on NHs in the Midwestern states. Analyzing data from different regions is important as climate, COVID-19 prevalence, COVID-19 related policies and attitude of the population vary from region to region. Further, most existing studies have considered only a narrow time frame (few months in 2020), which may miss valuable information on recurrent NH outbreaks.

This study examines a number of factors such as nursing home ratings, quality of care, staff shortage, PPE shortage, and $\mathrm{NH}$ ownership structure (for-profit vs non-profit vs government) to understand whether these factors are associated with COVID-19 cases in NHs in Midwestern states for the entire year of 2020 (Jan 12020 - Dec 27 2020). More specifically, the research question that guided this study is: What are the factors that shape the incidence of COVID-19 cases in NHs in Midwestern states?

\section{Methods}

Three datasets were combined from the Centers for Medicare \& Medicaid Services (CMS): 1. Star rating; 2. Provider information and 3. COVID-19 nursing home reported cases. The period examined is from Jan 1 - Dec 27, 2020, for the 12 Midwestern states in the population set (Illinois, Indiana, Iowa, Kansas, Michigan, Missouri, Minnesota, Nebraska, North Dakota, Ohio, South Dakota, and Wisconsin). This time period includes one year of data for the analysis, providing a more longitudinal picture of what occurred in nursing homes during the COVID-19 pandemic. Our sample size consisted of 4390 free-standing NHs, after removing cases with missing values.

We combined COVID-19 NH cases data with CMS and provider information. The provider information includes star ratings in three domains (health inspection rating, quality measure rating, staffing rating) and the star ratings range from one(low) to five (high). The health inspection domains are based on the three most recent standard surveys for each nursing home that result from any complaint investigation during the recent three years. The quality measure rating is based on indicators to describe the quality of care given in each nursing home. These measures address a wide range of functioning and health status in multiple care areas. The staffing domain is based on self-reported data from the nursing homes on the number of hours worked by their nursing staff, including Registered Nurse (RN) + Licensed Practical Nurse $(\mathrm{LPN})+$ Certified Nursing Assistants (CNA) hours and the number of residents in the facility.

Drawing on a recent study, we grouped nursing homes into three categories (19) based on the number of COVID-19 cases: those with (a) 10 cases or fewer, (b) 11 to 30 cases, and (c) more than 30 cases. Other measures used were self-reported information on ratings, overall star rating (1 to 5-star facilities), staff shortages, PPE shortage, number of beds, occupancy rate, and ownership status (profit, non-profit, government), and nursing staffing level hours per resident per day (RN, LPN, CNA). Ordinal logistic regression was used to examine the association between nursing home characteristics and incidence of COVID-19 cases.

Descriptive analyses in Table 1 show COVID-19 cases, Midwestern states, and NH characteristics. Three separate ordinal logistic regressions were conducted to examine the three domains associated with COVID-19 cases and assess the odds of high-performing facilities (4- or 5-star facilities) having more than 30 cases vs 11 to 30 cases vs 10 or fewer cases relative to low-performing facilities (1- to 3-star facilities). These factors were compared with reported resident COVID-19 cases and the statistical significance was tested between $\mathrm{NHs}$ having more than 30 cases vs 11 to 30 cases vs. 10 or fewer cases of COVID-19. Statistical measures used were ANOVA for nominal variables, Spearman $r$ for ordinal variables, and Pearson correlation tests for continuous variables.

Further analysis to understand the impact and effect of $\mathrm{NH}$ ownership structure on COVID-19 cases was done using the ANCOVA analysis to control for $\mathrm{NH}$ size.

All statistical analyses were performed by SPSS V. 27, and two-sided $\mathrm{p}$ values were considered significant at $\mathrm{p}<0.01$.

\section{Results}

Of the $4390 \mathrm{NHs}$ in 12 Midwestern states, when we compared the low-performing facilities and high performing $\mathrm{NHs}$, the high performers were less likely to have more than 30 COVID-19 cases for two of the CMS performance domains (health inspections, 520 [27.6\%] high performers vs 1363 [72.4\%] low performers; and staffing $773(41.1 \%)$ vs 1110 $(58.9 \%)$ (see Tables $1 \& 2$ ). Table 1 shows the number of nursing homes in each Midwestern state for each CMS domain, classified into high-performing and low-performing.

Table 3 provides the distribution of NH COVID-19 cases in each of the Midwestern States, with Ohio having the biggest share of NH COVID -19 cases and South Dakota having the lowest.

Illinois by far and away had the most large sized NHs. Ohio had the most NHs overall and was the state with the most medium sized facilities. Interestingly, as a percent of total beds, Missouri had the highest percent of middle sized NHs. 
THE JOURNAL OF NURSING HOME RESEARCH SCIENCESC

Table 1

Characteristics of High-Performing vs Low-Performing Nursing Homes Across 3 CMS Performance Domains in the Order of Number of Nursing Homes in Each State

\begin{tabular}{|c|c|c|c|c|c|c|c|}
\hline \multirow[b]{3}{*}{ Nursing home characteristics } & \multirow[b]{3}{*}{ All } & \multicolumn{4}{|c|}{ Nursing homes with ratings } & & \\
\hline & & \multicolumn{2}{|c|}{ Health inspection } & \multicolumn{2}{|c|}{ Quality measures } & \multicolumn{2}{|c|}{ Staffing } \\
\hline & & High performing & Low performing & High performing & Low performing & High performing & Low performing \\
\hline No. of nursing homes, No. (\%) & 4390 & $1484(33.8 \%)$ & $2906(66.2 \%)$ & $2793(63.6 \%)$ & $1596(36.4 \%)$ & $2351(53.6 \%)$ & $2039(46.4 \%)$ \\
\hline \multicolumn{8}{|l|}{ COVID-19 cases, No. (\%) } \\
\hline$\leq 10$ & $1295(29.5 \%)$ & $543(41.9 \%)$ & $752(58.1 \%)$ & $853(65.9 \%)$ & $442(34.1 \%)$ & $856(66.1 \%)$ & $439(33.9 \%)$ \\
\hline $11-30$ & $1212(27.6 \%)$ & $421(34.7 \%)$ & $791(65.3 \%)$ & $792(65.4 \%)$ & $419(34.6 \%)$ & $722(59.6 \%)$ & $490(40.4 \%)$ \\
\hline$>30$ & $1883(42.9 \%)$ & $520(27.6 \%)$ & $1363(72.4 \%)$ & $1148(61.0 \%)$ & $735(39.0 \%)$ & $773(41.1 \%)$ & $1110(58.9 \%)$ \\
\hline Certified beds, median, No. & 84 & 71 & 92 & 80 & 90 & 70 & 99 \\
\hline \multicolumn{8}{|l|}{ States, No. $(\%)$} \\
\hline Ohio & $827(18.8 \%)$ & $267(32.3 \%)$ & $560(67.7 \%)$ & $563(68.1 \%)$ & $264(31.9 \%)$ & $201(24.3 \%)$ & $626(75.7 \%)$ \\
\hline Illinois & $622(14.2 \%)$ & $209(33.6 \%)$ & $413(66.4 \%)$ & $305(49.0 \%)$ & $317(51.0 \%)$ & $293(47.1 \%)$ & $329(52.9 \%)$ \\
\hline Indiana & $485(11.0 \%)$ & $163(33.6 \%)$ & $322(66.4 \%)$ & $342(70.5 \%)$ & $143(29.5 \%)$ & $157(32.4 \%)$ & $328(67.6 \%)$ \\
\hline Missouri & $427(9.7 \%)$ & $162(37.9 \%)$ & $265(62.1 \%)$ & $207(48.6 \%)$ & $219(51.4 \%)$ & $141(33.0 \%)$ & $286(67.0 \%)$ \\
\hline Michigan & $393(9.0 \%)$ & $132(33.6 \%)$ & $261(66.4 \%)$ & $285(72.5 \%)$ & $108(27.5 \%)$ & $276(70.2 \%)$ & $117(29.8 \%)$ \\
\hline Iowa & $393(9.0 \%)$ & $139(35.4 \%)$ & $254(64.6 \%)$ & $245(62.3 \%)$ & $148(37.7 \%)$ & $273(69.5 \%)$ & $120(30.5 \%)$ \\
\hline Minnesota & $329(7.5 \%)$ & $100(30.4 \%)$ & $229(69.6 \%)$ & $242(73.6 \%)$ & $87(26.4 \%)$ & $317(96.4 \%)$ & $12(3.6 \%)$ \\
\hline Wisconsin & $325(7.4 \%)$ & $110(33.8 \%)$ & $215(66.2 \%)$ & $249(76.6 \%)$ & $76(23.4 \%)$ & $263(80.9 \%)$ & $62(19.1 \%)$ \\
\hline Kansas & $252(5.7 \%)$ & $90(35.7 \%)$ & $162(64.3 \%)$ & $138(54.8 \%)$ & $114(45.2 \%)$ & $82(32.5 \%)$ & $170(67.5 \%)$ \\
\hline Nebraska & $171(3.9 \%)$ & $55(32.2 \%)$ & $116(67.8 \%)$ & $108(63.2 \%)$ & $63(36.8 \%)$ & $121(70.8 \%)$ & $50(29.2 \%)$ \\
\hline South Dakota & $93(2.1 \%)$ & $35(37.6 \%)$ & $58(62.4 \%)$ & $58(62.4 \%)$ & $35(37.6 \%)$ & $74(79.6 \%)$ & $19(20.4 \%)$ \\
\hline North Dakota & $73(1.7 \%)$ & $22(30.1 \%)$ & $51(69.9 \%)$ & $51(69.9 \%)$ & $22(30.1 \%)$ & $65(89.0 \%)$ & $8(11.0 \%)$ \\
\hline
\end{tabular}

Table 2

Association Between Nursing Home Ratings of Health Inspections, Quality Measures, and Nurse Staffing Domains with COVID-19 Cases

\begin{tabular}{lll}
\hline $\begin{array}{l}\text { High-performing vs low - } \\
\text { performing nursing homes across } \\
\text { CMS domains }\end{array}$ & $\begin{array}{l}\text { Ordinal odds ratio of a nursing } \\
\text { home having } \mathbf{3 0} \text { cases vs } \mathbf{1 1} \text { to } \\
\mathbf{3 0} \text { cases vs } \mathbf{1 0} \text { cases }\end{array}$ & \begin{tabular}{l} 
P value \\
\hline Health inspection
\end{tabular} \\
Quality measures & $.70(.63-.79)$ & $<0.01$ \\
Staffing & $1.01(.90-.1 .12)$ & .94 \\
\hline
\end{tabular}

NHs with high ratings on health inspection and nurse staffing were less likely to have more than 30 COVID-19 cases vs facilities with 11 to 30 and vs facilities with 10 or fewer cases than were low-performing NHs (OR, 0.68; 95\% CI(.567-.823; $\mathrm{P}=<.01)$, (OR, 0.48; 95\% CI(.418-.557; $\mathrm{P}=$ $<.01)$. There was no significant association between high- vs low-performing NHs in the quality measures domains with COVID-19 cases.

While PPE shortages was a major concern in the early part of 2020, this study did not find any statistically significant impact of PPE on the incidence of COVID-19 cases (Table 4). There was no statistically significant association between self- reported staff shortages and COVID-19 cases.

Ownership of NHs (for-profit vs. not-for-profit vs. government) also showed a statistically significant $(\mathrm{p}<.001)$ association with incidence of COVID-19 cases (See Table 4). The data shows that for-profit NHs had more COVID-19 cases than not-for-profit and government owned. In this dataset, $60.4 \%$ were for-profit, $7.8 \%$ were government owned and $31.8 \%$ were not-for-profit nursing homes. In the category of NHs with less than 10 cases $53.2 \%$ were for-profit, $9.7 \%$ were government and $37.1 \%$ were not-for- profit. Whereas in NHs with over 30 cases of COVID-19, $67.9 \%$ were for-profit, $6.6 \%$ were government owned and $25.4 \%$ were not-for-profit. This could be because there are more for-profit nursing homes than government owned and non-profit.

To further understand the ownership effect, an ANCOVA analysis was performed to control for $\mathrm{NH}$ size measured by number of beds. The results of ANCOVA (see Table 5) clearly show a statistically significant $(\mathrm{F}=20.1 * * \mathrm{p}<0.01)$ association between ownership and COVID-19 cases after controlling for number of beds. We did a post hoc analysis (Bonferroni comparison) for $\mathrm{NH}$ ownership and found that there is statistically significant difference between for-profit vs government (mean difference $6.82 * * \mathrm{p}<0.01$ ) and statistically significant difference between for-profit and non-profit (mean 
NURSING HOME VULNERABILITIES AMID COVID-19 PANDEMIC

Table 3

State wide Distribution of Nursing Homes with COVID-19 Cases in Descending Order Based on the "All COVID-19 NH Cases"

\begin{tabular}{|c|c|c|c|c|c|c|c|c|}
\hline & $\begin{array}{c}\text { All Nursing } \\
\text { Homes } \\
\mathrm{N}=4390\end{array}$ & $\begin{array}{c}\leq 10 \text { COVID-19 } \\
\text { cases } \\
\mathrm{N}=1295(29.5 \%)\end{array}$ & $\begin{array}{c}\text { 11-30 COVID-19 } \\
\text { cases } \\
\mathrm{N}=1212(27.6 \%)\end{array}$ & $\begin{array}{c}>30 \text { COVID-19 } \\
\text { cases } \\
\mathrm{N}=1883(42.9 \%)\end{array}$ & $\begin{array}{l}\text { All COVID-19 } \\
\text { NH Cases } \\
\mathrm{N}=135948\end{array}$ & $\begin{array}{c}\text { Small (<50 beds) } \\
673(15.5 \%)\end{array}$ & $\begin{array}{c}\text { Size* } \\
\text { Medium }(50-150 \\
\text { beds) } 3188 \\
(73.6 \%)\end{array}$ & $\begin{array}{c}\text { Large }(>150 \\
\text { beds) } 473 \\
(10.9 \%)\end{array}$ \\
\hline \multicolumn{9}{|l|}{$\mathrm{N}(\%)$} \\
\hline Ohio & $827(18.8 \%)$ & $196(23.7 \%)$ & $229(27.7 \%)$ & $402(48.6 \%)$ & $28347(20.9 \%)$ & $73(8.9 \%)$ & $685(83.9 \%)$ & $58(7.1 \%)$ \\
\hline Illinois & $622(14.2 \%)$ & $136(21.9 \%)$ & $129(20.7 \%)$ & $357(57.4 \%)$ & $26083(19.2 \%)$ & $39(6.3 \%)$ & $408(66.3 \%)$ & $168(27.3 \%)$ \\
\hline Indiana & $485(11.0 \%)$ & $114(23.5 \%)$ & $135(27.8 \%)$ & $136(48.7 \%)$ & $16804(12.4 \%)$ & $32(6.7 \%)$ & $390(81.4 \%)$ & $57(11.9 \%)$ \\
\hline Missouri & $427(9.7 \%)$ & $93(21.8 \%)$ & $99(23.2 \%)$ & $235(55.0 \%)$ & $15948(11.7 \%)$ & $16(3.8 \%)$ & $359(84.9 \%)$ & $48(11.3 \%)$ \\
\hline Michigan & $393(9.0 \%)$ & $134(34.1 \%)$ & $122(31.0 \%)$ & $137(34.9 \%)$ & $10786(7.9 \%)$ & $49(13.0 \%)$ & $266(70.7 \%)$ & $61(16.2 \%)$ \\
\hline Iowa & $393(9.0 \%)$ & $152(38.7 \%)$ & $108(27.5 \%)$ & $133(33.8 \%)$ & $9209(6.8 \%)$ & $126(32.3 \%)$ & $255(65.4 \%)$ & $9(2.3 \%)$ \\
\hline Minnesota & $329(7.5 \%)$ & $134(40.7 \%)$ & $86(26.1 \%)$ & $109(33.1 \%)$ & $7836(5.8 \%)$ & $82(25.2 \%)$ & $219(67.2 \%)$ & $25(7.7 \%)$ \\
\hline Wisconsin & $325(7.4 \%)$ & $133(40.9 \%)$ & $101(31.1 \%)$ & $91(28.0 \%)$ & $6797(5.0 \%)$ & $54(16.8 \%)$ & $249(77.3 \%)$ & $19(5.9 \%)$ \\
\hline Kansas & $252(5.7 \%)$ & $94(37.3 \%)$ & $81(32.1 \%)$ & $77(30.6 \%)$ & $6016(4.4 \%)$ & $99(39.4 \%)$ & $144(57.4 \%)$ & $8(3.2 \%)$ \\
\hline Nebraska & $171(3.9 \%)$ & $67(39.2 \%)$ & $57(33.3 \%)$ & $47(27.5 \%)$ & $3629(2.7 \%)$ & $43(25.3 \%)$ & $115(67.6 \%)$ & $12(7.1 \%)$ \\
\hline North Dakota & $73(1.7 \%)$ & $16(21.9 \%)$ & $26(35.6 \%)$ & $31(42.5 \%)$ & $2269(1.7 \%)$ & $31(42.5 \%)$ & $37(50.7 \%)$ & $5(6.8 \%)$ \\
\hline South Dakota & $93(2.1 \%)$ & $26(28.0 \%)$ & $39(41.9 \%)$ & $28(30.1 \%)$ & $2242(1.6 \%)$ & $29(31.2 \%)$ & $61(65.6 \%)$ & $3(3.2 \%)$ \\
\hline
\end{tabular}

difference $3.77 * * \mathrm{p}<0.01$ ) and there was no significant difference between not-for-profit and government ownership (mean difference $-3.05 \mathrm{p}=.09$ ). This additional analysis indicates that for-profit $\mathrm{NHs}$ were significantly different from both government-owned and non-profit NHs, when it came to the number of COVID-19 cases.

COVID-19 cases also increased with the number of beds in the nursing homes. NHs with over 30 COVID-19 cases had an average of 114.8 beds, whereas NHs with less than 10 COVID19 cases had only 70.9 beds on average. This association is statistically significant $(\mathrm{p}<.01)$ (See Table 4). However, there was a statistically significant but small negative correlation between occupancy rate and COVID-19 cases, NHs with less than 10 COVID-19 cases had slightly higher occupancy than NHs with over 30 cases of COVID-19. The average occupancy rate was $65.8 \%$ and there was not much variance in this when compared based on COVID-19 cases. There was also a low negative correlation between number of beds and occupancy rate $\mathrm{r}=-0.155 \mathrm{p}<0.01$ (data not shown).

There was also a statistically significant $(\mathrm{p}<.01)$ association between star ratings of NHs and the incidence of COVID-19 cases (Table 4). The data shows there were fewer nursing homes with 5-star rating in the over 30 COVID-19 cases. Of the NHs that had 1-star rating $57.6 \%$ had more than 30 COVID-19 cases, whereas only $29.5 \%$ of NHs that had 5-star rating had more than 30 COVID-19 cases. Similarly, only $19.4 \%$ NHs with 1-star rating had less than 10 cases of COVID-19 while $39.1 \%$ of NHs with 5-star rating had less than 10 cases of COVID-19.

While there was no significant association between self- reported staff shortages and COVID-19 cases, staff hours per resident of RN and CNA, had a statistically significant $(\mathrm{p}<.001)$ negative association. i.e., the more RN and CNA hours per resident, the lower the number of COVID-19 cases. In NHs with less than 10 COVID-19 cases, the staffing hours per resident was on average $96 \mathrm{RN}$ hours and 1.69 CNA hours where it was only $.61 \mathrm{RN}$ hours and $1.46 \mathrm{CNA}$ hours in NHs with more than 30 COVID-19 cases (see Table 4). However, in the case of LPN hours, there was positive association with COVID-19 cases, i.e., as the number of LPN hours increased, so did the incidence of COVID-19 cases. In NHs that had less than 10 COVID-19 cases, LPN hours per resident was on average .72 hours, but in NHs that had more than 30 cases, there were .77 LPN hours on average. The difference is small, but it was statistically significant with $\mathrm{p}<.001$. On further analysis, we also found that while there is a positive correlation for RN and CNA hours with star rating (RN $.432^{* *} \&$ CNA $.307 * * \mathrm{p}<.01)$, there was a statistically significant negative correlation between LPN hours and star rating (LPN -.073** $\mathrm{p}<.01)$. In addition, $\mathrm{RN}$ and CNA hours were negatively correlated with number of beds (RN -206**, CNA -.118**, $\mathrm{p}<.01$ ), LPN hours were positively correlated with number of beds (LPN .116**, p<.01).

\section{Discussion}

The distribution of NH COVID-19 cases among the Midwestern states seems to be highly correlated with size and population density of these states. However, Illinois was leading in the number of COVID-19 cases until October 2020 
THE JOURNAL OF NURSING HOME RESEARCH SCIENCESC

Table 4

Nursing Home Characteristics, Covid-19 Factors, and Star rating

\begin{tabular}{|c|c|c|c|c|c|}
\hline Variables & $\begin{array}{l}\text { All Nursing Homes } \\
(\mathrm{N}=4390)\end{array}$ & $\begin{array}{l}\leq 10 \text { COVID-19 cases } \\
\mathrm{N}=1295(29.5 \%)\end{array}$ & $\begin{array}{l}\text { 11-30 COVID-19 cases } \\
\mathrm{N}=1212(27.6 \%)\end{array}$ & $\begin{array}{l}>30 \text { COVID-19 cases } \\
\mathrm{N}=1883(42.9 \%)\end{array}$ & Chi-square p- Values \\
\hline & Mean(SD) or N(\%) & Mean(SD) or N(\%) & Mean(SD) or N(\%) & $\operatorname{Mean}(\mathrm{SD})$ or $\mathrm{N}(\%)$ & \\
\hline & \multicolumn{5}{|c|}{ Outcome Measures no. (\%) } \\
\hline Shortage of Licensed Nurse Staff (RN+LPN) & $1211(27.6 \%)$ & $354(29.2 \%)$ & $318(26.3 \%)$ & $539(44.5 \%)$ & 0.99 \\
\hline Shortage of Nurse Aides & $1263(28.8 \%)$ & $386(30.6 \%)$ & $329(26.0 \%)$ & $548(43.4 \%)$ & 1.00 \\
\hline Shortage of Clinical Staff (MD+NP+PA) & $152(3.5 \%)$ & $42(27.6 \%)$ & $48(31.6 \%)$ & $62(40.8 \%)$ & 0.95 \\
\hline \multirow[t]{2}{*}{ Shortage of Other Staff } & $668(15.2 \%)$ & $200(29.9 \%)$ & $170(25.4 \%)$ & $298(44.6 \%)$ & 1.00 \\
\hline & \multicolumn{5}{|c|}{ COVID-19 Factors no. (\%) } \\
\hline Adequate Current supply of N95 Masks & $4235(96.5 \%)$ & $1247(29.4 \%)$ & $1167(27.6 \%)$ & $1821(43.0 \%)$ & 0.99 \\
\hline Adequate Current supply of Eye Protection & $4275(97.4 \%)$ & $1262(29.5 \%)$ & $1176(27.5 \%)$ & $1837(43.0 \%)$ & 0.97 \\
\hline Adequate Current supply of Gowns & $4281(97.5 \%)$ & $1261(29.5 \%)$ & $1182(27.6 \%)$ & $1838(42.9 \%)$ & 0.86 \\
\hline Adequate Current supply of Gloves & $4317(98.3 \%)$ & $1268(29.4 \%)$ & $1197(27.7 \%)$ & $1852(42.9 \%)$ & 0.67 \\
\hline Adequate Current supply of Surgical mask & $4282(97.5 \%)$ & $1260(29.4 \%)$ & $1183(26.6 \%)$ & $1839(42.9 \%)$ & 0.96 \\
\hline \multirow[t]{2}{*}{ Adequate Current supply of Hand Sanitizer } & $4319(98.4 \%)$ & $1270(29.4 \%)$ & $1194(27.6 \%)$ & $1855(42.9 \%)$ & 0.36 \\
\hline & \multicolumn{4}{|c|}{$\begin{array}{l}\text { Nursing Home Structure } \\
\text { Ownership }\end{array}$} & $\begin{array}{l}\text { ANOVA } \\
<.001\end{array}$ \\
\hline For-profit (H) & $2651(60.4 \%)$ & $689(26.0 \%)$ & $683(25.8 \%)$ & $1279(48.2 \%)$ & \\
\hline Government & $344(7.8 \%)$ & $125(36.3 \%)$ & $94(7.8 \%)$ & $125(36.3 \%)$ & \\
\hline \multirow[t]{2}{*}{ Not-for-profit } & $1395(31.8 \%)$ & $481(34.5 \%)$ & $435(31.2 \%)$ & $479(34.3 \%)$ & \\
\hline & \multicolumn{4}{|l|}{ Size and Occupancy } & Correlation \\
\hline Number of Beds & $93.4(50.7)$ & $70.9(37.1)$ & $84.0(48.9)$ & $114.8(51.2)$ & $0.523 * *$ \\
\hline \multirow[t]{2}{*}{ Occupancy Rate\% } & $65.8(16.8)$ & $69.2(18.2)$ & $64.5(17.3)$ & $64.1(15.1)$ & $-0.069 * *$ \\
\hline & \multicolumn{4}{|c|}{ Overall star rating, no. (\%) } & $-0.211 * *$ \\
\hline 1 Star & $566(12.9 \%)$ & $110(19.4 \%)$ & $130(23.0 \%)$ & $326(57.6 \%)$ & \\
\hline 2 Star & $787(17.9 \%)$ & $180(22.9 \%)$ & $198(25.2 \%)$ & $409(52.0 \%)$ & \\
\hline 3 Star & $811(18.5 \%)$ & $223(27.5 \%)$ & $214(26.4 \%)$ & $374(46.1 \%)$ & \\
\hline 4 Star & $975(22.2 \%)$ & $293(30.1 \%)$ & $277(28.4 \%)$ & $405(41.5 \%)$ & \\
\hline \multirow[t]{2}{*}{5 Star } & $1251(28.5 \%)$ & $489(39.1 \%)$ & $393(31.4 \%)$ & $369(29.5 \%)$ & \\
\hline & \multicolumn{5}{|c|}{$\begin{array}{l}\text { Nursing home characteristics Staffing } \\
\text { Mean(SD)(\%) }\end{array}$} \\
\hline RN Staffing Level Hours per resident per day & $.81(.52)$ & $.96(.75)(35.2 \%)$ & $.82(.40)(28.2 \%)$ & $.69(.33)(36.6 \%)$ & $-.204 * *$ \\
\hline \multicolumn{6}{|l|}{ LPN Staffing Level } \\
\hline Hours per resident per day & $.76(.34)$ & $.72(.36)(28.4 \%)$ & $.77(.35)(28.0 \%)$ & $.77(.30)(43.6 \%)$ & $.050 * *$ \\
\hline \multicolumn{6}{|l|}{ CNA Staffing Level } \\
\hline Hours per resident per day & $1.57(.57)$ & $1.69(.78)(31.9 \%)$ & $1.60(.47)(28.1 \%)$ & $1.46(.40)(40.0 \%)$ & $-.156 * *$ \\
\hline
\end{tabular}

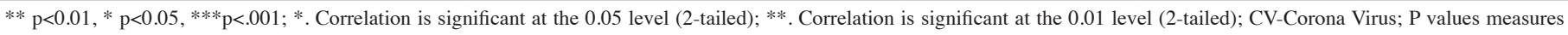

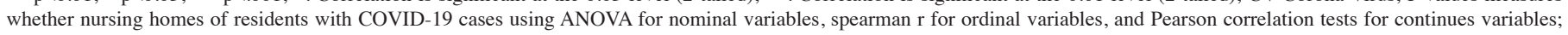
Ownership $\mathrm{P}$ value $=\mathrm{ANOVA}$; Overall star rating $\mathrm{P}$ value $=$ spearman $\mathrm{r}$

(21). The metropolitan city of Chicago (in Illinois) with high population density could have been the reason for Illinois to be leading in COVID-19 cases until Oct 2020. Chicago and Illinois were also one of the first cities and states to experience more COVID-19 cases early on in the pandemic (22). When data from Nov and Dec 2020 were included in the analysis, Ohio led in number of cases. In all Midwestern states, COVID19 cases doubled when the Nov and Dec 2020 data were added to the data from Jan-Oct 2020 (21).

From National Organization of State Offices of Rural Health (NOSORH) data, Ohio is the only Midwestern state with no frontier population, while S. Dakota and N. Dakota had more than $30 \%$ frontier population (23). Frontier areas have very low population density. State-by-state differences in NH COVID-19 rates could also be due to differences in state-level policies on social distancing, mask wearing, level of community spread, 
NURSING HOME VULNERABILITIES AMID COVID-19 PANDEMIC

Table 5

Association between Ownership and COVID-19 cases after controlling for number of beds

\begin{tabular}{|c|c|c|c|c|c|}
\hline \multicolumn{6}{|c|}{ Analysis of Covariance (ANCOVA) } \\
\hline Source & Sum of Squares & df & Mean Square & F & Partial Eta Squared \\
\hline Number of All beds & 877436.29 & 1 & 877436.29 & $1582.4 * *$ & .27 \\
\hline Ownership type & 22346.12 & 2 & 11173.06 & $20.1 * *$ & .01 \\
\hline Error & 240101.3 & 4330 & 554.5 & & \\
\hline
\end{tabular}

and variation in testing and reporting. Variations in reporting format, case definitions and update frequency were also indicated as barrier in another study (11).

The number of beds was positively associated with higher COVID-19 cases, consistent with prior studies (in other States) $(11,13,18)$. There have been some studies that have found that smaller NHs, especially greenhouse NHs fared better in the COVID-19 pandemic (13). The stated reasons were that smaller NHs' residents have better psychosocial well-being, such NHs are usually not-for-profit, and that the resident case mix usually have less minority population (that are often at higher mortality risk) (13). It could also be that larger nursing homes have higher number of staff; spread of COVID-19 through staff is another aspect that some studies have indicated (24), where surges where highly correlated with increase in staff and resident cases. Staff testing was also not fully implemented in around $12 \%$ of facilities according to another study (25). This finding is consistent with other studies that indicate smaller sized nursing homes are associated with better quality care (5, 26). Since, COVID-19 is highly contagious in crowded areas, the analysis checked for associations with overcrowding i.e. occupancy in these NHs. However, our findings show that $\mathrm{NH}$ COVID-19 cases are negatively correlated with occupancy rate. One possible explanation for this negative relationship is larger NHs tend to have lower occupancy rates.

This study also found a correlation between NH ownership status and COVID-19 cases. From our analysis, for-profit NHs were more likely to have higher rates of COVID-19 cases. Other studies have reported similar findings $(14,18)$ and a news report (27) also noted that for-profit nursing homes are not faring well in controlling COVID-19. While other studies report a correlation between NH ownership and COVID-19, our analysis included multiple tests to confirm the statistically significant relationship between ownership and COVID-19. Potential explanations for this finding include the tendency for there to be more beds in for-profit facilities, the facilities being larger in general and also usually located in urban areas that has larger proportion of minority population (28). Our study further indicated that for-profit NHs had more cases even after controlling for $\mathrm{NH}$ size. In this study, there was a negative correlation between for-profit ownership and 5-star rating and with RN and CNA staffing hours. Poor star rating is associated with lower RN staffing hours and high staff turnover rates (29).
Also, for-profit status is associated with higher LPN staffing hours, which could indicate that for-profits are utilizing LPNs (to reduce costs), instead of RNs.

A limitation of the current study is that other factors such as health and functional status of the resident at admission, rate of resident admissions from the community or from the hospital and the population density of the city or town in which the $\mathrm{NH}$ is located, could also affect the COVID-19 cases in NHs. However, these factors could not be part of the analysis as CMS database does not have these measures.

Across the 12 Midwestern states, high-performing NHs, especially in terms of health inspection ratings and nurse staffing, had fewer COVID-19 cases than low-performing NHs. This is consistent with prior studies that have focused on other states (19). These findings do indicate that such performance measures are important and they do indicate poor staffing and poor health standards needs to be addressed (10). Poor health standards and nurse staffing shortages can make an $\mathrm{NH}$ more vulnerable to future pandemics.

Our study findings also reveal another nursing staff -related insight; specifically, higher RN and CNA hours correlated with lower COVID-19 cases, whereas LPN staff hours lead to higher COVID-19 cases. These findings are consistent with other nursing home studies that link quality care with higher and more qualified staffing (30). However, more research is needed that examines whether it is the reduction of RNs or something specific to LPN training that impacted the COVID19 cases. We also found from further analysis that LPN hours were negatively correlated with star ratings, indicating a link to quality care. LPN hours was also positively correlated with number of beds, indicating that larger NHs tend to hire more LPNs and from this study and others, we know that the size of the NH is positively associated with higher COVID-19 cases.

\section{Conclusion and Implications}

While vaccination campaigns are well underway and will limit the spread of COVID-19, nursing homes are still vulnerable to mutations of the virus and other endemics. The frailty, age and multiple chronic conditions of this population make them especially vulnerable and the safety of older adults in NHs should remain top priority. This study of NHs in Midwestern states indicate that the $\mathrm{NH}$ factors that are most 


\section{THE JOURNAL OF NURSING HOME RESEARCH SCIENCESC}

associated with a higher prevalence of COVID-19 cases are size of the nursing home/number of beds, for-profit ownership, star ratings, and RN and CNA hours per resident per day. We depart from prior studies on this topic by examining selfreported NH data for the entire year of 2020 (Jan 12020 - Dec 27 2020) and by specifically focusing on all the Midwestern states. Our analysis findings imply the potential to use a minimal set of indicators to predict the future incidence of COVID-19 pandemic (and other endemics) among $\mathrm{NH}$ residents and inform on appropriate policy considerations to reduce NH vulnerabilities in this context. Future studies could consider state-wide policies to limit community spread and impact on COVID-19 cases in NHs. In addition, studies could also evaluate the impact of the adoption of COVID-19 related policies within NHs such as visitation and staff testing on the incidence of COVID-19 cases and evaluate the impact of providing more resources in terms of qualified staffing and care practices that promote strong infection control on the spread of diseases such as COVID-19. Future studies could consider integrating external data, such as government policy changes, magnitude of the COVID-19 outbreak and attitudes of the population in that region towards the pandemic and the restrictions imposed, with the CMS data to understand how that impacted COVID-19 cases in NHs in that region.

Conflict of Interest: Priya Nambisan: No conflict of Interest to report. Mohammed Abahussain: No conflict of Interest to report. Colleen Galambos: No conflict of Interest to report. Bo Zhang: No conflict of Interest to report. Elizabeth Bukowy: No conflict of Interest to report; Edmund Duthie: . No conflict of Interest to report.

Funding sources: This research did not receive any funding from agencies in the public, commercial, or not-for-profit sectors. All authors meet criteria for authorship as stated in the Uniform Requirements for Manuscripts Submitted to Biomedical Journals. All authors contributed to the analysis of the data, interpretation of the results and writing of the paper.

\section{References}

1. AARP. COVID-19 Nursing Home Resident and Staff Deaths: AARP Nursing Home Dashboard. AARP. Published March 2021. Accessed March 28, 2021. https://www. aarp.org/ppi/issues/caregiving/info-2020/nursing-home-covid-dashboard.html

2. Ouslander JG, Grabowski DC. COVID-19 in Nursing Homes: Calming the Perfect Storm. J Am Geriatr Soc. 2020;68(10):2153-2162. doi:10.1111/jgs.16784

3. Centers for Medicare and Medicaid. Upcoming Requirements for Notification of Confirmed COVID-19 (or COVID19 Persons Under Investigation) Among Residents and Staff in Nursing Homes.; 2020.

4. Barnett ML, Grabowski DC. Nursing Homes Are Ground Zero for COVID19 Pandemic. JAMA Health Forum. 2020;1(3):e200369. doi:10.1001/ jamahealthforum.2020.0369

5. Shippee TP, Henning-Smith C, Kane RL, Lewis T. Resident- and Facility-Leve Predictors of Quality of Life in Long-Term Care. The Gerontologist. 2015;55(4):643655. doi:10.1093/geront/gnt148

6. Wolff JL, Starfield B, Anderson G. Prevalence, Expenditures, and Complications of Multiple Chronic Conditions in the Elderly. Arch Intern Med. 2002;162(20):2269. doi:10.1001/archinte.162.20.2269

7. Zhang X, Dou Q, Zhang W, et al. Frailty as a Predictor of All-Cause Mortality Among Older Nursing Home Residents: A Systematic Review and Meta-analysis. J Am Med Dir Assoc. 2019;20(6):657-663.e4. doi:10.1016/j.jamda.2018.11.018

8. Chow N, Fleming-Dutra K, Gierke R, et al. Preliminary Estimates of the Prevalence of Selected Underlying Health Conditions Among Patients with Coronavirus Disease 2019 - United States, February 12-March 28, 2020. Morb Mortal Wkly Rep. 2020;69(13):382-386. doi:10.15585/mmwr.mm6913e2
9. Fallon A, Dukelow T, Kennelly SP, O'Neill D. COVID-19 in nursing homes. QJM Int J Med. 2020;113(6):391-392. doi:10.1093/qjmed/hcaa136

10. Davidson PM, Szanton SL. Nursing homes and COVID-19: We can and should do better. J Clin Nurs. 2020;29(15-16):2758-2759. doi:https://doi.org/10.1111/ jocn. 15297

11. Abrams HR, Loomer L, Gandhi A, Grabowski DC. Characteristics of U.S Nursing Homes with COVID-19 Cases. J Am Geriatr Soc. 2020;68(8):1653-1656. doi:10.1111/jgs.16661

12. Gorges RJ, Konetzka RT. Factors Associated With Racial Differences in Deaths Among Nursing Home Residents With COVID-19 Infection in the US. JAMA Netw Open. 2021;4(2):e2037431. doi:10.1001/jamanetworkopen.2020.37431

13. Zimmerman S, Dumond-Stryker C, Tandan M, et al. Nontraditional Small House Nursing Homes Have Fewer COVID-19 Cases and Deaths. J Am Med Dir Assoc. 2021;22(3):489-493. doi:10.1016/j.jamda.2021.01.069

14. Chatterjee P, Kelly S, Qi M, Werner RM. Characteristics and Quality of US Nursing Homes Reporting Cases of Coronavirus Disease 2019 (COVID-19). JAMA Netw Open. 2020;3(7):e2016930. doi:10.1001/jamanetworkopen.2020.16930

15. He M, Li Y, Fang F. Is There a Link between Nursing Home Reported Quality and COVID-19 Cases? Evidence from California Skilled Nursing Facilities. J Am Med Dir Assoc. 2020;21(7):905-908. doi:10.1016/j.jamda.2020.06.016

16. Li Y, Temkin-Greener H, Shan G, Cai X. COVID-19 Infections and Deaths among Connecticut Nursing Home Residents: Facility Correlates. J Am Geriatr Soc. 2020;68(9):1899-1906. doi:10.1111/jgs.16689

17. Bui DP, See I, Hesse EM, et al. Association Between CMS Quality Ratings and COVID-19 Outbreaks in Nursing Homes - West Virginia, March 17-June 11, 2020 Morb Mortal Wkly Rep. 2020;69(37):1300-1304. doi:10.15585/mmwr.mm6937a5

18. Unruh MA, Yun H, Zhang Y, Braun RT, Jung H-Y. Nursing Home Characteristics Associated With COVID-19 Deaths in Connecticut, New Jersey, and New York. J Am Med Dir Assoc. 2020;21(7):1001-1003. doi:10.1016/j.jamda.2020.06.019

19. Figueroa JF, Wadhera RK, Papanicolas I, et al. Association of Nursing Home Ratings on Health Inspections, Quality of Care, and Nurse Staffing With COVID-19 Cases. JAMA. 2020;324(11):1103. doi:10.1001/jama.2020.14709

20. Akoglu H. User's guide to correlation coefficients. Turk J Emerg Med. 2018;18(3):91-93. doi:10.1016/j.tjem.2018.08.001

21. Nambisan, P., Abahussain, M., Duthie, E., Galambos, C., Zhang, B., \& Bukowy, E. Factors Associated with Increase in COVID-19 Cases in Nursing Homes: A Study of Nursing Homes in Midwestern States. J Am Geriatric Soc. 20211;69(S1):S217. https://doi.org/10.1111/jgs.17115

22. Wang J. Data from over 200 U.S. urban areas highlight need for more aggressive countermeasures. UChicago News. https://news.uchicago.edu/story/coronavirushitting-larger-cities-harder-how-should-they-respond. Published March 21, 2020 Accessed April 22, 2021.

23. Hirsch S. Everything You've Always Wanted to Know About Rural ? NOSORH Natl Organ State Off Rural Health Httpsnosorhorg. Published online September 2014:44.

24. McMichael TM, Currie DW, Clark S, et al. Epidemiology of Covid-19 in a LongTerm Care Facility in King County, Washington. N Engl J Med. 2020;382(21):20052011. doi:10.1056/NEJMoa2005412

25. Konetzka RT, Gorges RJ. Nothing Much Has Changed: COVID-19 Nursing Home Cases and Deaths Follow Fall Surges. J Am Geriatr Soc. 2021;69(1):46-47. doi:https://doi.org/10.1111/jgs.16951

26. Judith A. Lucas EdD B APN, PhD CAL, Timothy J. Lowe PhD L LSW, et al. The Relationship Between Organizational Factors and Resident Satisfaction with Nursing Home Care and Life. J Aging Soc Policy. 2007;19(2):125-151. doi:10.1300/ J031v19n02_07

27. For-profit nursing homes are 'worst performers' in new COVID-19 analysis - News McKnight's Long Term Care News. Published February 19, 2021. Accessed March 27, 2021. https://www.mcknights.com/news/for-profit-nursing-homes-are-worstperformers-in-new-covid-19-analysis/

28. Sugg MM, Spaulding TJ, Lane SJ, et al. Mapping community-level determinants of COVID-19 transmission in nursing homes: A multi-scale approach. Sci Total Environ. 2021;752:141946. doi:10.1016/j.scitotenv.2020.141946

29. Gandhi A, Yu H, Grabowski DC. High Nursing Staff Turnover In Nursing Homes Offers Important Quality Information: Study examines high turnover of nursing staff at US nursing homes. Health Aff (Millwood). 2021;40(3):384-391. doi:10.1377/ hlthaff.2020.00957

30. Spilsbury K, Hewitt C, Stirk L, Bowman C. The relationship between nurse staffing and quality of care in nursing homes: A systematic review. Int J Nurs Stud. 2011;48(6):732-750. doi:10.1016/j.ijnurstu.2011.02.014 